\title{
Sustainable development of production in Russia: an informative aspect
}

\author{
Igor G. Vidyaev $^{1,}$, , Nikita V. Martyushev ${ }^{1}$, Ju. A. Kozlikina ${ }^{1}$ \\ ${ }^{1}$ Tomsk polytechnic university, 634050, Lenina Avenue, 30, Tomsk, Russia
}

\begin{abstract}
This paper is devoted to the study of the problems of introduction of the concept of sustainable development of production at modern enterprises. The paper substantiates the necessity of application of this concept at enterprises, gives reasons hindering this process. In addition, the analysis of the notion of sustainable development of production, wherein this process is represented as development of production by means of rational and economical use of resources oriented to provision of a long-term competitive advantage, was conducted in the paper. Moreover, the paper presents the basic principles of successful introduction of the concept of sustainable development of production. By the example of Toyota Company the benefits, which can be derived by an enterprise from application of this concept, were shown.
\end{abstract}

\section{Introduction}

Nowadays the notion "sustainable development" has been deeply rooted in modern scientific and professional literature. It can be met in different branches of research and spheres of activity: economics, sociology, mathematics, ecology, medicine, politics and others.

This happened due to adoption of the UNO Declaration on Environment and Development in 1992 in Rio de Janeiro, which proclaimed the obligations of the countries on basic recommendatory principles of achieving of the sustainable development model by human civilization [1].

After approval of the Decree of the Russian Federation (RF) president "on the RF Strategy for environmental protection and provision of sustainable development", Russia has officially embarked on the course of realisation of the Concept of sustainable development [2]. However, in spite of the fact that almost 20 years have passed since the adoption of this Decree, no active movement of the state in this direction is observed.

In our opinion, in this case the root problem consists in the approach to the solution of this task. All actions on sustainable development of Russia are taken at a federal level, the less number of actions - at a regional level, and at an enterprise level - less than that of the regional one. Under this circumstance the level of production, where the product itself is produced, the major natural resources are consumed, modern technologies are applied, environmental pollution takes place, is ignored. The reason consists in the fact that owners of industruial enterprises do not pay proper attention to this problem as the region of their interest concerns the increase of profitability of their business in the current situation rather than protection of environment and conservation of the natural-resource potential of the state. For this purpose the state has the leverage over enterprises; however, this mechanism has not been actuated in Russia so far. Even if this mechanism were triggered under present-day conditions, it, to a greater degree, would be similar to the "stick" method, that is, the influence by means of administrative-legal methods on the administration and owners of an organisation. But such approach will not have a proper effect for sustainable development of the society.

As we envision it, the initiative in the solution of this problem should belong to the enterprises themselves; but until their managers see an opportunity to benefit from it, they will not initiate realisation of the concept of sustainable development.

For that reason we envision substantiation of the possibility of realisation of the sustainable development concept at the level of production and benefits, which the management of organisations will gain as a result of its introduction, as the main goal of the paper.

In order to achieve this goal we, first, have to solve the problem of definition of the concept "sustainable development of the production system" [3].

In modern science there are many definitions of the concept "sustainable development". And it is necessary to note their variety beginning from treating them as economic growth, providing satisfaction of current and future needs of the society, an ending with considering them as stable, at times balanced, development of society [4].

\footnotetext{
${ }^{\text {a }}$ Corresponding author: vig@tpu.ru
} 


\section{Materials and methods}

Different interpretations of the notion of sustainability of a social-economic system are connected not only with the complexity of the analysed phenomenon, but also with the initial inaccuracy of the translation of "sustainable" into the Russian language. When translated, the word "sustainable" means "supportive, continuous, lasting", not "stable". In the Russian language the notion "sustainable" implies a different meaning. It is defined as a capability of the system to revert to the original state after the influence on it from the outside. But is it always required for such system as production? It seems that it is not. After all, it is the external influence that is sometimes capable of transferring production to a principally different trajectory of development. Therefore it seems natural to us to consider sustainable development as a constant and continuous process of development, but with separate additions.

\section{Results and discussion}

If we turn to the primary source of the UNO Decree on Environment and Development, it becomes clear to what its creators wanted to pay attention - to the "price" that the humanity has to pay for the constant economic growth: deterioration of the ecology of the planet, a decrease in the natural-resource potential of the planet, orientedness of modern economies and states to satisfaction of the current needs, not the needs of the humanity in the future. Hence the appeal of the Decree to a careful treatment of the nature, resources, people and their rational use with orientation to the future generations, application of new environmentally appropriate technologies, the rational use of the existing production spaces and industrial zones is evident. It is this aspect that was highlighted by the specialists of the Institute of the World Bank as crucial when defining the notion of sustainable development, considering this process as rational management of the produced, natural and human capitals.

Summing up everything aforesaid, the conclusion about the necessity of turning the modern industries into more rational, careful, resource-efficient ones in consumption of the existing resources springs to mind. Does this condition contradict to the policy of most enterprises and industries? No, it does not. Therefore, any enterprise always functions in the conditions of limitation of financial, human, material and other resources, which is a reality of existence and survival, but not something that contradicts functioning.

On the other hand, sustainable development should be perceived as a complex process of development, within which the economic, social and ecological human needs are satisfied, that is, an interaction of the interests of business owners, society, including employees and customers, future generations takes place. Without taking the demands of these interested parties into consideration, no single modern enterprise can exist. Ignoring the interests of one of the parties immediately influences the efficiency of business in short-term and long-term prospects.

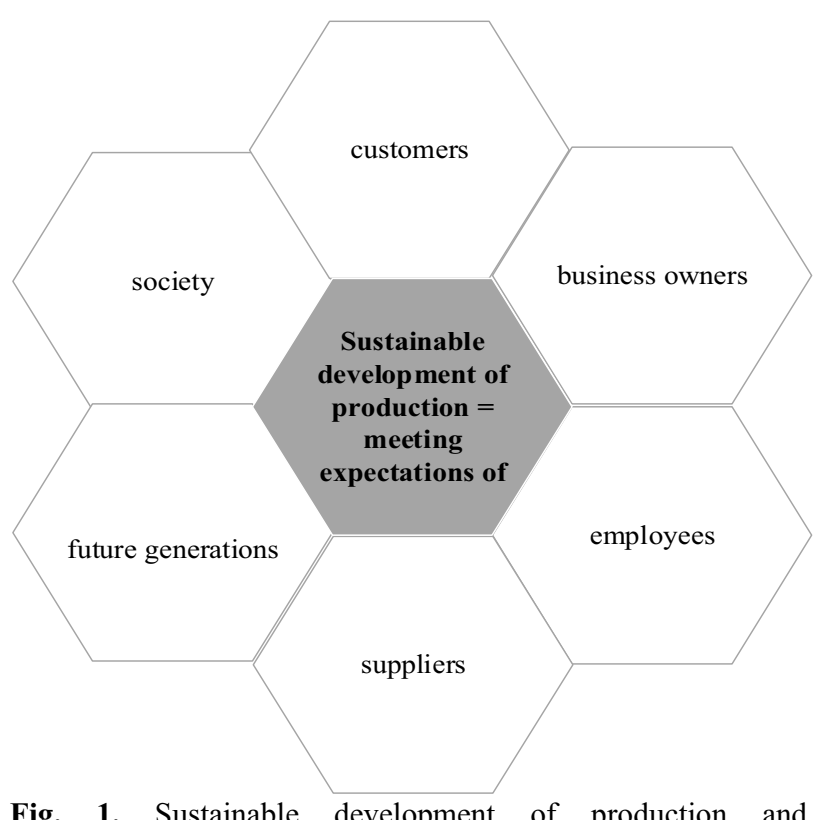

Fig. 1. Sustainable development of production and expectations of the interested parties

Hence, sustainable development of production in the framework of this paper will imply a continuous and complex process of development of production due to rational and careful exploitation of the available resources, technologies and spaces, oriented to meeting demands of business owners, society, future generations and providing successful long-term existence of a company in the competitive market.

Reasoning from the above-mentioned analysis of the basic theses of the notion "sustainable development of production", there are opportunities for realisation of this concept at the level of production; besides, no serious contradictions to current peculiarities of running a modern business are envisioned. Then a planned question arises: what hinders the introduction of this concept at the level of enterprises and production?

The basic answer to it is incommensurability of expenditures, profits and risks when implementing this concept. The reasons for appearance of this problem are the following:

First of all, it is the absence of clearly defined methodology of sustainable development of production with orientation to minimization of expenditures and algorithmization of introduction of this concept. Most companies, when making reports on its sustainable development, consider tripersonality of the concept (economics-socium-ecology), but they view these elements separately from each other, but by no means fully, in the interrelation.

Secondly, there is a lack of information on the experience of the concept introduction at enterprises and on the results of this process. Now in Russia the only consulting organisation - the Group of Companies (GC) "Orgprom" - is engaged in the propaganda of the concept of sustainable development, and it happens only at the level of an enterprise. At the level of the state no 
active work in this direction is undertaken. In this connection a certain information vacuum emerges on the territory of Russia because of the limitedness of the GC "Orgprom" company's capabilities and unwillingness of the authorities to provide the process of sustainable development within our country. In many respects the appearance of this problem is connected with the third reason.

Thirdly, there is a lack of experts in this field, prepared to teach the management and employees of enterprises the concept of sustainable development.

Undoubtedly, the reasons can be complemented by great expenditures on introduction of ecologically clean technologies, presence of a small number of Russian technology and equipment, oriented to solution of such problems, ambiguity of economic benefits from application of this concept, poor demand on the part of consumers for acquisition of more expensive ecologically pure products, the absence of clear requirements to utilization of the products on the territory of Russia and many others. However, all these reasons depend on the reasons mentioned above by us, which are connected largely with a low level of studying of the concept of sustainable development of production in a theoretical-methodological and practical aspect, and, consequently, on the complexity of its perception by the management and owners of enterprises.

\section{Methodology of sustainable development of production}

In the framework of the current paper we do not set ourselves a task to describe the whole methodology of sustainable development of production, mechanisms of management of this process at an enterprise taking into account the provision of long-term benefits, the system of monitoring and evaluation of the current state of production from the positions of sustainability of development. We will dwell only on the principles, on which this methodology should base, as well as on the benefits derived from its introduction by all interested parties.

We envision that the basic principles of the methodology of sustainable development should base upon the basic principles of sustainable development, formulated within the framework of the UNO Conference on Environment and Development (Rio-deJaneiro, 1992), upon the rules of realisation of the concept of social responsibility of corporates (corporate social responsibility, CSR), as well as upon methods of rational and economical organisation of production (first of all, these are the concepts of economical production and quality management). The whole complex of suggested methods, to be more exact their part, which will be used in the framework of this concept, should provide satisfaction of not only the current demand of customers (which corresponds to, for example, the tasks of the customer relationship management (CRM) approach - a customer-oriented approach), but also the modern demands of society. This process thereby forms such new line of production and enterprise development as a socially oriented approach.

We will refer the following steps to the basic principles of methodology:

1. Organise a quality service for a customer providing a full range of products at the current moment of time and in the future if required.

2. Be responsible to both present and future society (socium).

3. Show respect to partners and suppliers, setting them challenging tasks and assisting them in selfperfection.

4. Provide environmental safety of production and manufactured products.

5. Strive for continuous, sustainable development of production.

6. Standardize accomplishment of objectives, including social and environmental ones, which is a basis for continuous improvement and delegation of authorities. Introduce social and environmental standards of production activity.

7. Create favourable conditions of labour at an enterprise, including environmentally safe surrounding of the production.

8. Provide the growth of life quality of employees.

9. Be frank with society and employees. Provide information transparency of a business.

10. Constantly search and introduce new knowledge, innovation products, technologies, which provide sustainable development of an enterprise.

11. Introduce the system of monitoring, evaluation and control over sustainable development of production. Use visual inspection so that not a single problem went unnoticed.

12. Involve people in the process of sustainable development, train leaders, unordinary people and organise teams, professing sustainable development.

We envision the principles described above as a methodological basis of the concept of sustainable development. They do not contradict modern methods of production management, but, on the contrary, they complement and specify them to some degree. As to the complexity of their interaction and mutual influence, it is possible to say, studying, for instance, the experience of Toyota Company, that they are not observed. Thus, while Taiichi Ohno was developing and introducing the basic principles of economical production, the Committee on environmental policy of production was established in the company in 1963. In 1992, on its basis the Committee on environmental policy of Toyota under the direction of the company president was established, which is in force to this day. In the same year this Committee developed the Charter of global environment of the company, wherein the plan of actions on improvement of environment was described.

Simultaneously, under the chairmanship of the President of the company, in 1989 the Committee on the civil activity of the company was established, the task of which was a realisation of social measures and projects in the interests of the state and citizens of Japan.

It is worth noting that the whole social, economic, environmental policy of Toyota is "tied up" with the 
company president; it is he who is a guarantor of its realisation within the framework of the company. In addition it should be noted that this fact has provided definite benefits for the company. According to the organisation, thus having enhanced the effectiveness of their business.

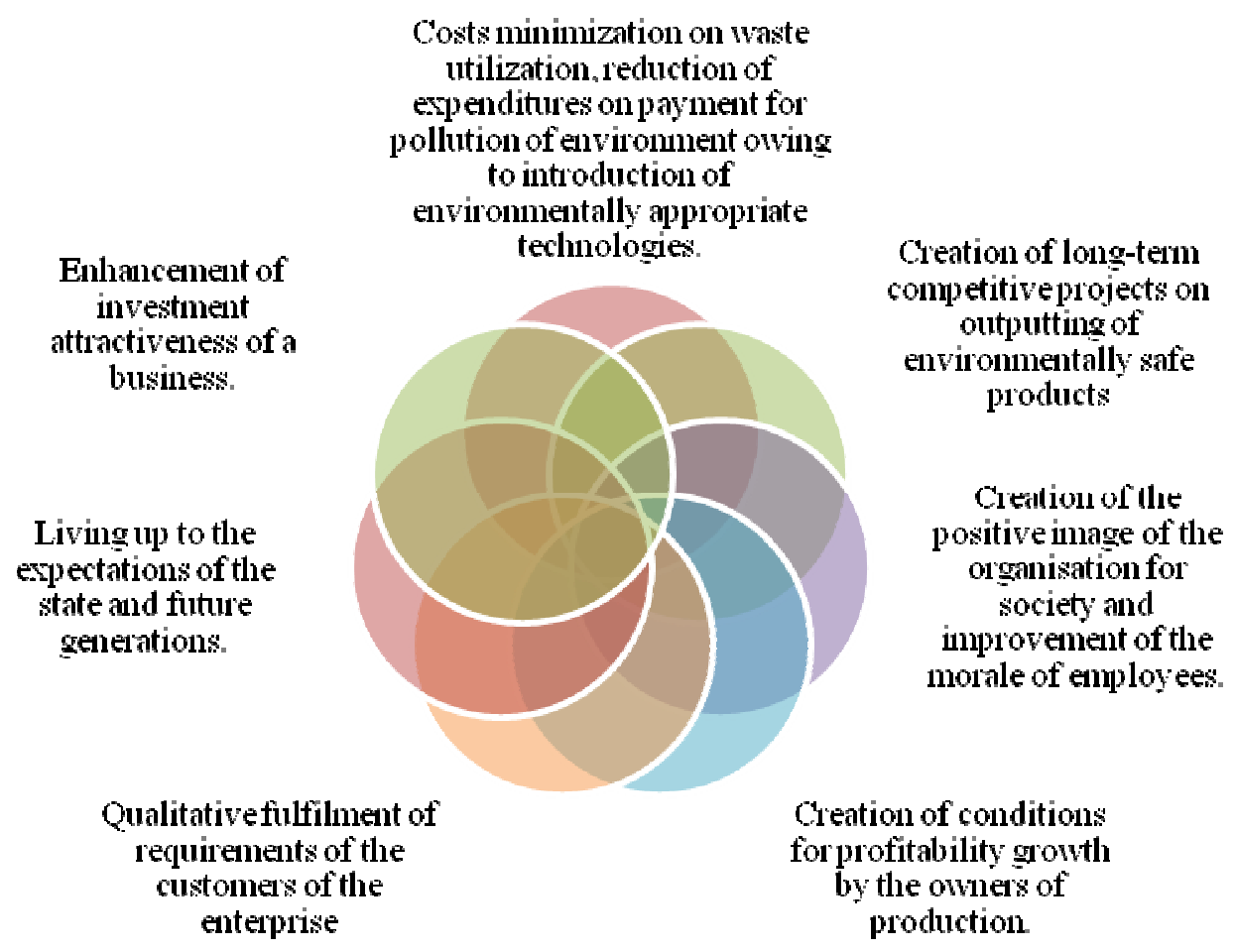

Fig. 2. The main results of production, the achievement of which should provide the concept of sustainable development of production

studies of the specialists of Toyota company, the mere realisation of the measures on the management of environmental activity of the organisation allowed them among the first to prepare and put a hybrid car «Toyota Prius» into mass production; to reduce maintenance expenditures, such as electric power and waste utilization expenditures; to receive additional revenues from selling of products and from royalty; to refuse expenditures connected with suits by means of taking measures on preventing the pollution; to gain nonmaterial effects such as improvement of the corporative image and the morale of the employees and other effects [5].

On the basis of the analysis of all effects, obtained by Toyota company from introduction of the concept of sustainable development, studying of the experience of other companies, let us formulate the main results, the obtainment of which should be ensured by the methodology of sustainable development of production [6]. These results are presented in Figure 2.

All above-enumerated results represent the benefits, which were obtained by the companies, predominantly foreign ones, due to introduction of the concept of sustainable development, thus having increased their competitiveness not only at present, but also in the longterm period. Introduction of the concept allowed them to take a fresh look at their activity, to reconsider the priorities of development and to provide meeting the expectations of different interested parties of the

\section{References}

1. Report of UN Conference on environment and development (Rio de Janeiro, June 3-14, 1992)

2. About Strategy of the Russian Federation for environmental protection and providing a sustainable development. The decree of the Russian President from 2/4/1994 No. 236

3. V.A. Los', A.D. Ursule, Sustainable development: manual (M oscow, Agar, 2000)

4. A.I. Tatarkin, D.S. Lvov, A.A. Kuklin, Modeling of a sustainable development as condition of increase of economic security of territory (Yekaterinburg: Urals publishing house university, 1999)

5. Introduction of the guidelines in Toyota and the Charter of global environment Toyota. The Information portal "Toyota Motors Corporation" Access mode: http://www.toyotaglobal.com/company/history_of_toyota/75years/text /leaping_forward_as_a_global_corporation/chapter3 /section $2 /$ item1.html;

6. Chronology of policy on environment protection of Toyota. Information portal "Toyota Motors Corporation", Access mode: http://www.toyotaglobal.com/sustainability/report/sr/99/pdf/p92_95.p df 